\title{
How East Asian classrooms may change over the next 20 years
}

\author{
Tak-Wai Chan \\ Graduate Institute of Network Learning Technology \\ National Central University, Taiwan
}

\begin{abstract}
Our schools have been experiencing three overlapping waves of technology adoption since the mid-1980s: the personal computer lab wave, the online learning wave, and the digital classroom wave. In this position paper, I tried to explain why we are now at the onset of the digital classroom wave, why it will cause great changes in education and why those changes could not occur prior to the digital classroom wave. By proposing a series of conjectures, I described with some confidence how classrooms in Taiwan may change. I also believed that some schools in other East Asian countries may experience similar changes. Basically, the classroom will undergo a transition from a pursuit of individualization and productivity in the first stage to the pursuit of personalization and global citizenship in the second stage. The linkage between the first stage and the second stage is also the linkage between the Internet world and the classroom world, which are now virtually separate. Technology adoption is determined by the availability of that technology, and we researchers in the field have little influence over it; however, we can build compelling, sustainable and 'disseminable' experimental digital classroom sites to set out classroom reform. To shed light on the development and dissemination of experimental sites, I draw parallels between Deng's economic reform of China and classroom reform. In the process of building digital classroom experimental sites, we are revealing fundamental problems, setting out fundamental changes and hailing the advent of a new era of formal education.
\end{abstract}

Keywords: Bloom's 2-sigma productivity problem, digital classroom, e-book, learning-by-teaching, one-to-one classroom, personalization

\section{Introduction}

Unless all parents one day work from home, unless the network communications bandwidth one day increases to the point where interface-to-interface interactions can supplant face-to-face interactions, schools will continue to exist. Even if these 
two 'unless' conditions become true, schools will continue; this is because, with so many virtual worlds in which children will engage or reside in the future, the school may be the most precious place for nurturing real-world, face-to-face socialization. Schools will not disappear but change. When and how schools will change, however, is not clear. In this position paper, I take the liberty of proposing a set of conjectures about how elementary school classrooms in Taiwan may change as they increasingly adopt digital technology. I suggest that one of the possible evolutionary paths is from individualization and productivity to personalization and global citizenship. I deem that these conjectures, to some extent, can be extended to elementary classrooms around East Asia due to a significant common ground: the legacy of Confucian teaching exerts its influences throughout the Greater China region, even extending to countries such as Japan and Korea. Confucius was a great teacher, and therefore teaching is regarded as a highly respected career in Asian societies; children are taught to look up to their teachers from a very young age. Also, their parents attribute doing well in school to hard work, and not doing well to laziness. This explains why most East Asian schools demand that students complete much homework. Moreover, parents believe that education is the only way that one can change one's personal fate and that of the family. Even today, some parents are willing to go hungry for their children if it could help the younger generation receive a better education. Education matters most in Asian families.

In this paper, I also take the liberty of telling stories. Such stories or anecdotes help to explain complicated issues, shed light on developing strategies and generate conjectures-bold or moderate.

\section{Story 1: my research journey}

My past research experience has shaped my view of the future. In the mid-1980s, I was a doctoral student in a computer science department in the USA. In 1988, grounded in Vygotsky's hypothesis (1978) on zone of proximal development, my advisor and I proposed the concept of the learning companion and a learning environment consisting of two virtual characters: a virtual learning companion and a virtual tutor (Chan and Baskin, 1988; 1990; Chan 1991). During learning, the human student could collaborate or compete against the learning companion under the guidance of the virtual tutor. Thus, a standalone computer can also provide richer social contexts in a virtual learning environment. However, implementing my system required a LISP machine costing US\$50,000 and ran a language used only for artificial intelligence. When I finished my thesis in the late 1980s, I said to myself that my system could not be used in 20 years: such a 
machine was prohibitively expensive.

After receiving my $\mathrm{PhD}$, I began work at a university in Taiwan. Together with my graduate students, I connected two IBM-compatible personal computers (PCs) via a cable to develop a system for synchronous collaborative and competitive learning games. We then extended the system for experiments in our departmental computer lab containing around 50 PCs. In 1992, when we published our work, we called our system a futuristic intelligent classroom (Chan et al. 1992). Subsequently, we conducted a sequence of studies on synchronous networked learning using connected computers (Chan 1996; Chan and Chou 1997; Chang et al. 2003b). By the late 1990s, I realized that PCs were still too bulky for the classroom, while laptops were still too expensive. In 1999 we developed inexpensive wireless response clickers, called EduClick, for enhancing teacher-student interactions during question-and-answer activities (Huang et al. 2001; Liang et al. 2005). We later discovered that we were not the first to conceive the design of such clickers, but such devices are now gaining popularity in classrooms around the world.

In 2000, I had an opportunity to lead a four-year learning technology project, a large project involving dozens of professors from across Taiwan. A subproject of that project was the building of EduCity, a large online learning community (Chan et al. 2001; Chang et al. 2004, Chang et al. 2007). EduCity is composed of a hierarchy of communities: EduCity itself represents the entire community, consisting of school websites called EduTowns. An EduTown represents a school, and is composed of the websites of the classes in that school called EduVillages. An EduVillage represents a class, and is composed of the personal websites of the students and the teacher in that class called EduCitizens. In addition to this hierarchical structure, EduCity provides students with online resources and activities. For example, using the technologies that are today referred to as Web2.0, EduTowns (schools) can adopt online application programs called service items, which are provided by the EduCity. An EduTown can also develop its own service items and, if desired, share them with other EduTowns. The system also supports teacher collaboration for developing learning materials and lesson plans as open content. Furthermore, every EduCitizen, who may be a teacher or a student, can open an online course in EduCity.

Another subproject was the continuation of research on future classrooms. Some colleagues investigated mobile learning (Chen et al., 2003; Chang et al. 2003a; Lai et al. 2007), where they treated the outdoors and nature as a part of a future 
classroom. Others studied real physical classrooms, initially using WebPads, which are pen-based and wireless enabled computers, and later using Tablet PCs as they became available (Wang et al. 2004).

More than 1.5 million students participated in EduCity activities; and operations were transferred to the largest telecommunication company in Taiwan. Since then, our team has continued to work on classrooms where every student uses a computer to learn. Together with a group of international researchers, we call such classrooms one-to-one (1:1) classrooms (Chan et al. 2006).

Twenty years have passed since I received my doctoral degree. In retrospect, I find that my research journey was not only a journey of exploring educational innovations brought about by technology, it was also a journey of chasing after technology. For example, many video games today can depict hordes of virtual characters when run on a PC - they do not require the bulky, expensive machines of twenty years ago. Before long, multiple virtual characters will also be prevalent in game-based learning (to this end, my colleagues and I (Chen et al. 2007; Chen et al. in press) are now working on animal companions). As technology continues to advance and as its applications permeate every social sector, technology adoption in schools has grown into an overt challenge for both researchers and practitioners.

\section{Conjecture 1: A third wave-the digital classroom wave-is imminent}

Technology adoption is the process of technology diffusion on large scales. Its determining factor is technology availability, but technology adoption requires a measure of technology maturity as well. Whether schools or parents can financially afford the technology needed by children, whether the technology is light enough to carry between home and school, and whether the technology is handy enough for reading and writing-all these contribute to technology availability and maturity. We researchers, on the other hand, primarily study the design of new technology for pedagogy and learning with scant consideration given to accessibility issues.

As it happens, driven by technology availability, schools have experienced three waves of technology adoption over the last 25 years, one after another, one overlapping another, and one impacting schools more enormously than another. The first wave, the PC lab wave, started in the mid-1980s. For the first time, schools were able to offer students opportunities to learn about and use computers. 
At that time, a school could afford to purchase a limited number of PCs, with each one treated as a piece of equipment, rather similar to that found in a science lab. Also, PCs were large enough that schools instituted rooms, one or two labs per school, in which at most a few dozens computers were contained. Thus, even though PC laboratories were managed as laboratories, PCs began to be accessible at schools.

The second wave, the online learning wave, started in the mid-1990s. A rapid aggregation of individual contributions to the Internet led to an accumulation of a large volume of online learning resources and online learning community activities. Currently, the Internet is accessible to schools in Taiwan in the sense that every school has a website accessible by everyone through the Internet; almost every classroom has a desktop computer physically connected to the Internet. Teachers can use a desktop computer in their classrooms; and if the classroom has a projector, it can be employed to instruct students using online resources.

Our four-year learning technology project was conducted at the peak of the Internet upsurge. During that period of time, the most noticeable phenomenon to me was that the two environments we were committed to establishing (the online learning environment and the future classroom learning environment) were two separate worlds (Fig. 1). No matter how rich the online learning resources or how vibrant the online communities created within EduCity, they could be accessible to students only at home or after school in the PC laboratory. Without computers at hand, students in the classroom could not benefit from all the advantages of the Internet. The limited and sporadic use of the Internet by classroom teachers was inadequate. The situation remains much the same even today: online learning and classroom learning are two separate worlds.

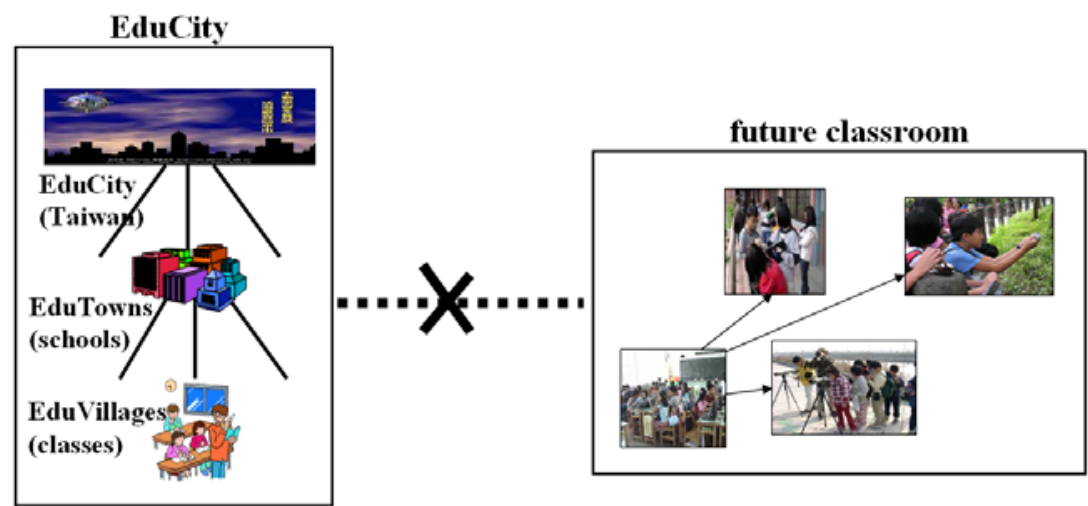

Fig 1 The Internet and the classroom are two separate worlds. 
Yet, since the beginning of the second wave, the situation has begun to change. Early this decade when we conducted the future classroom subproject, WebPads or Tablet PCs cost around US\$2000 each. Presently, we are using low-cost laptops (or netbooks) that cost about US\$300.. Not only has the price dropped, but these laptops are also smaller, lighter and easier to use. Moreover, people are now considering electronic e-readers, intending to replace printed books. In the future, some of these readers will be made of electronic paper (e-paper) that is thin, flexible, as crisply readable as paper, and even roll-able. We can envisage an ultimate personal device for future schooling that is based on the co-evolution of low-cost laptops and e-paper-based readers. In the remainder of this paper, I shall collectively refer to low-cost laptops, e- readers, or other computing devices used by students in a classroom as "e-books", a reminder that most such devices are intended to replace the current printed textbooks.

The availability of e-books and interactive electronic whiteboards (e-boards) in the classroom has signaled the advent of a third wave of adoption - the digital classroom wave. The classroom had not been significantly impacted by digital technology until the arrival of this newest wave. It has already begun and will certainly be increasingly evident over the next decade. The digital classroom is a new medium of instruction for both teachers and students, one where e-books replace textbooks and pencils, and e-boards replace blackboards and chalk. Digital classrooms will impact schools much more extensively and profoundly than in the previous two waves. It should be noted that while I regard e-boards as less essential than e-books (more on this later in the paper), e-boards will enter classrooms earlier than e-books, since teachers can control e-boards more easily than students' e-books. In this respect, I use the term digital classroom to refer to a classroom consisting of students' e-books as well as an e-board, or a projector connected to a desktop PC.

As discussed, technology accessibility ultimately determines the arrival of a new wave of adoption. Had the Internet not appeared in the mid-1990s, and had low-cost, wireless-enabled laptops emerged sooner than Internet (computers requiring cables were overly cumbersome in a classroom setting), then the chronology of the online learning wave and the digital classroom wave would have been reversed.

\section{Conjecture 2: classrooms undergo radical change over the next 20 years}

While availability issues are at the forefront of any adoption wave, continuity of 
innovation (Rogers 2003) governs the pace of adoption. Continuity of innovation indicates how closely innovation matches user practice. The closer the match is, the faster the adoption. Thus, if continuous innovation leads to evolution, then discontinuous innovation leads to revolution.

One may remember that the process whereby electronic calculators and PCs respectively replaced slide rules and typewriters, which went away quietly and unnoticeably, until one day all the slide rules and typewriters had seemed to disappear suddenly. Both the electronic calculator and the PC represent continuous innovations; they could rapidly and completely replace slide rules and typewriters, respectively. Continuous innovations are natural extensions of what has always been used, but possess more powerful and indispensible functions. For example, e-boards resemble but extend traditional blackboards and chalk, while e-books imitate but magnify traditional textbooks and pencils. E-boards and e-books are continuous innovations.

Not long ago, sponsored by the Taiwan Ministry of Education, many elementary schools in Taiwan acquired e-boards. Each school set up multiple classrooms to use these e-boards. Some of these schools also purchased the EduClick system, serving to enhance student-teacher interactions when using an e-board in the classroom. Ten years after we designed EduClick, I am pleased to see its prevalence in Taiwan. However, such clickers are only transitional products, one day to be replaced by e-books. I cannot predict how fast classrooms will acquire e-books and e-boards in Taiwan or in Asia within 20 years, but I am certain that these accessible and continuous innovations will respectively replace blackboards and textbooks (textbooks are currently seen as indispensable in Asian classrooms). This will be similar to the replacement of traditional distance learning using television and video tapes by Internet-based programs during the online learning wave. With such replacements in place, students will no longer rely only on their ears and eyes to engage with teachers, but also rely on their hands on their e-books (much more often than with pens and paper in traditional classrooms).

Over the next 20 years, there will be a great change in learning in the classroom - the primary environment of formal education-driven by a set of core classroom pedagogical models enabled by e-books with e-boards or projectors.

This conjecture is my main conjecture, supported by the next eight conjectures proposed below. All eight conjectures can also be seen as a portrait of one of 
possible evolution paths of this impending change.

\section{Story 2: a meeting with "Ms. Liu”}

Not many teachers are interested in using digital technology, but most teachers are concerned about the educational ideals they cannot meet. Individualization is one such ideal, an ideal that many teachers are willing to strive for. Our research team once had a meeting with an experimental school, in a below-average economic status area. Previously, for two classes in that school over a period of one year, we had conducted experiments twice a week for half an hour before classes started. Ms. Liu, the teacher of one class, knew about our experiments on small group collaboration for Chinese language composition in her class, but she did not participate directly. Our plan for the next academic year was more ambitious - intervention in Ms. Liu's class. Ms. Liu is a serious teacher, but she does not enthuse about computers. She learned our intentions from her principal. She was anxious. The Principal therefore called this meeting.

Before the meeting, I received from the principal a piece of paper on which Ms. Liu had listed her questions: "What on earth does teaching look like in this experiment? What should I do in the classroom? Will students really benefit? What are the advantages compared to my usual teaching style?' While I was certain that Ms. Liu had read the project outline I had prepared for the principal, she still had multiple questions: she was predominantly wondering why we wanted to use computers in her class. I, of course, understood that such intervention might induce substantial changes in her classroom practice, and that she would have to expend a great deal of effort to collaborate with us. As such, the meeting was a challenge for me, especially as I recognized that Ms. Liu might be representative of many serious teachers. I knew I had to pin my explanations down to her questions.

In the principal's office sat the principal, Ms. Liu, a few of my research team members, and I. Ms. Liu, as expected, expressed her concerns and questioned our need to introduce computers into her class. I responded by saying, "Ms. Liu, as you've seen, in your class students will have computers on their desks. You can imagine that in the future, every student in your class will spend a considerable amount of time interacting with computers. They will learn directly from their computers, or they will learn together in small groups mediated by computers. Meanwhile, from your computer at your desk, you can immediately discern whose answers are right or wrong, good or poor. You can then help individual students according to their particular needs." 
In describing the teaching scenario of a digital classroom, I used concepts that I thought Ms. Liu should know about. 'You must have heard about teacher-centered instruction and student-centered instruction. The digital classroom is a form of student-centered instruction," I explained. As Ms. Liu appeared to muse on my remarks I continued, "Look! When students have spent a fair amount of time interacting with their computers, their computers can react differently according to their responses and needs. This achieves individualization to some degree. At that time, the role of a teacher grows much more challenging: she doesn't simply monitor students' learning statuses using her computer; she becomes her students' personal tutor, personal coach, personal mentor, and personal advisor. She must ensure that every student catches on!” When I was finished, Ms. Liu still mused on my words, without further response. The meeting switched to another topic.

A week later, the school arranged a meeting with parents from Ms. Liu's class. The principal, Ms. Liu and I took turns explaining to the parents why we had set up this experimental class. When it was her turn, Ms. Liu mentioned the term 'individualization' several times rather than 'student-centered instruction.' I was puzzled at her choice of words, as she should have been more familiar with the meaning of student-centered instruction.

Ms. Liu preferred 'individualization' to 'student-centered instruction' probably because she believed that she should pursue individualization in her teaching. If she had mentioned the benefits of student-centered instruction, it could have brought to mind its contrast: the less preferred teacher-centered instruction she had previously practiced, the notion which she did not want to be labeled with.

\section{Conjecture 3: the e-book will prevail over the e-board}

Will the digital classroom enable individualization? Unfortunately, before answering this question, we must first clarify another issue: an expected war between e-book-centered instruction and e-board-centered instruction in digital classrooms, extending the long-standing war between student-centered instruction and teacher-centered instruction in traditional classrooms. This is the first crossroad in the evolutionary path of classrooms. If e-board-centered instruction wins, then, students will continue to perceive the same voice, the same visual scene, the same gestures and body movements of the same teacher, with uniformity and simultaneity, just as they do in a traditional classroom. Some teachers may perceive that their e-boards animate the teacher-led instruction; 
however, livening up lessons does not necessarily bring essential changes into the classroom. If, on the other hand, e-book-centered instruction wins, students will spend a considerable amount of time in the classroom with their e-books, in the way that I had explained to Miss Liu. In other words, the teacher may still use the e-board for instruction, possibly for conducting mini-lessons lasting for five or more minutes, but not as frequently as the blackboard is used in traditional classrooms. A classroom can emphasize e-board-centered instruction without e-books, yet a classroom lacking e-book-centered instruction should not include e-books, simply because there is no way to justify their need. Once parents begin to purchase e-books for their children, e-books use in the classroom will expand. I conjecture in the end that e-book-centered instruction will prevail. This is further supported by the need for individualization, as explained in the next section.

\section{Remarks}

Here I make two remarks. The first remark is an obvious one. E-book-centered instruction implies that e-books will be integrated with most curriculum-content material, marking the onset of frequent use of a completely different medium in the classroom. The second remark is about dichotomies such as e-board-centered instruction and e-book-centered instruction, as well as teacher-centered instruction and student-centered instruction. Some researchers hesitate to use dichotomies lest they oversimplify phenomena. But dichotomies highlight and address different emphases, enabling us to better compare and understand the differences, especially when explaining different positions of a complex issue. Without dichotomies we may lose the big picture. Nobody denies that the classroom in Taiwan is teacher-centered, dominated by the voice of the teacher. Dichotomies matter, lest we lose direction when opportunity for fundamental change emerges.

\section{Conjecture 4: Individualization will be increasingly emphasized}

Students differ in aptitudes, pace of learning, interests, and many other facets. Unfortunately, individualization is extremely difficult to establish in traditional classroom settings, where a single teacher has to face thirty or more students. A teacher may take into account the current achievement level of some students as a reference for teaching, and hope that the majority of students can live up to that level. One style of teaching, unfortunately, cannot fit all-some students get left behind as others move ahead.

Prior to the advent of this wave, many teachers were already in favor of individualization; but the traditional classroom setting was such that attaining 
individualization was arduous. That every student can catch up, that every student can be a star and a champion, that every student can pursue personal interests - these are all timeless and undeniable goals for every teacher and every educator. Yet, without individualization, these goals are impossible; without individualization, there is no real change in classrooms. As such, individualization will take on a prominent role in the digital classroom wave and become an exigency. Emphasis on individualization is inevitable, and is currently more pressing than at anytime in the history of formal schooling.

The notion of individualization has been around for years. For example, the intelligent tutoring system research community has taken individualization vigorously since John Self proposed the student model concept (1974). Online learning has triggered more study on student profiles collected online and the emergence of educational data mining research.

In the context of the classroom, individualization refers to taking individual differences into account, in both the design and practice of classroom instruction. Individualization has multiple factors to consider. The social interaction aspect of individualization favors individual learning more than group learning, as it is easier to adjust individual learning to become adaptive to different students' needs as compared to group learning. Yet this does not imply that group learning must preclude individualization. Though the main focus in group learning pertains to social interactions and dynamics during learning, a student's e-book can provide individual support to that student during group learning. In the context of collaborative learning, competitive group learning, game-based learning, and other emerging learning pedagogical models that involve group learning, the understanding how to form groups, how to adjust constantly learning activities, how to give differentiated feedback to individual students with regard to their individual student differences all represent salient research concerns.

The second aspect is the scale of the learning task. Individualization on a large scale refers to the appropriateness of a curriculum for a student. At a medium scale, individualization is whether a problem, such as an arithmetic problem, is appropriate for the student. Individualization at a small scale can refer, for example, to whether a particular action of a student and a corresponding response from the student's e-book are appropriate while a student works on a problem.

The third aspect of individualization is the learning pace. Assuming that one class period represents our unit of time, we can consider these choices: do we assign all 
students to complete the same amount of work at the same pace in class period, or should we allow them different amounts of time.

Realizing all aspects of individualization in a digital classroom is no easy task. Here I elaborate only on one aspect-learning pace-by referring to an experiment we conducted in a class of third grade elementary students as an example. First, students in Taiwan are normally distributed into different classes according to their previous levels of achievement. Thus, every class has a few students who are particularly slow in learning or are encountering behavior problems. If we divide a typical class of 30 students into three groups - the fast group, the medium group, and the slow group - then each group will include 10 students. It is often the case that at least half of the teacher's total attention is paid to the slow group, and especially to the slowest few students.

In one of our experiments, to respect differences in learning paces, we have adopted individual learning. Quietly and independently, students learn elementary mathematics concepts through solving example problems by interacting with their e-books. When a student runs into difficulty, the student receives immediate feedback from the e-book or seeks additional help by clicking a 'raise hand' icon in the e-book to notify the teacher. Before a student grows overly frustrated, the teacher's computer notifies the teacher through the monitoring tool of the digital classroom system. The teacher then walks towards the student and whispers to that student. Alternatively, instead of walking over to the student, the teacher and the student may communicate silently and privately via their computers. In other words, in individual learning, a teacher's computer can communicate with the students' e-books, allow the teacher to monitor each student's progress, and, if needed, provide timely and tailored assistance. When those students have finished with the assigned examples, they read other books while the rest continue. In some class periods, in the time the 10 students of the fast group finished 20 examples, the slowest five students completed only five examples. This was a big gap in learning pace among the different groups: the fastest third is at least four times faster than the slowest sixth. If the teacher does not pay special attention to these students and assigns these students different work at school and at home, then when the gap continues to enlarge, the slowest students might give up on attaining success in mathematics.

But a classroom is a social place. The description of individual learning above is somewhat contrary to our usual impression of a classroom. Individual learning cannot override other forms of learning all of the time. Classroom time is 
distributed in proportions to individual learning, group learning, and teacher-led instruction (or expository lecturing). The most direct way to realize individualization, however, is through individual learning, as depicted in our experiment, even though a student's e-book can provide individual assistance in group learning. Moreover, self-paced learning can only be realized in individual learning. Therefore, I believe that individual learning will ultimately occupy a considerable proportion of classroom time.

\section{Remarks}

I make three remarks here. The first is about activities using e-books and the e-board alternately. We have defined e-board-centered instruction as the emergent phenomenon in classrooms in which the e-board is used frequently by the teacher. Actually, the e-board in the classroom serves another important function: student use. Many digital classroom activity models call for students to alternate between the use of e-books and the e-board. Here the 'little big teacher' is an example model, a model I advocate and foresee to be quite common in the future. It is a learning-by-teaching model that parallels what teachers in Taiwan do when preparing for their own classes. The teacher first chooses a topic that is difficult for students to grasp, such as fractions. Students do what they usually do in the classroom. First they learn about the topic and subsequently engage in related practice. To further enhance their learning of the topic, each student independently prepares a mini-lecture about fractions by reading about the concept in the teacher's manual for the textbook (its use is not restricted to teachers!) and by accessing recommended supplemental materials on the web. After the students have prepared their own lectures, groups are formed. Members discuss, and then combine their lecture materials into a single lecture. Then groups in the class are paired for competition. Each group in each pair takes turn to present their prepared lectures to the class using the e-board. The rest of the class then uses their e-books to vote for the group in that pair that performed better. This little big teacher model illustrates that, by taking advantage of both the e-board and the e-books, a digital classroom can become something akin to a physical platform, much like a theater stage where students can perform what they have prepared and practiced - in class, after class or at home.

The second remark is that it is easy to assume that e-book-centered instruction falls into two categories: individual learning and group learning. Does the choice between individual learning and group learning mark the second crossroad in the evolutionary path of the digital classrooms? The answer is negative, obviously. Actually, in a digital classroom, there are two genres of group learning. If the 
group is comprised of an entire class, then students may engage in playing whole class games such as EduBingo (Chang et al. 2009) or AnswerMatching (Cheng et al. 2009) to practice arithmetic computations. If, on the other hand, a class is divided into smaller groups, then numerous group learning models are available, from peer tutoring and peer collaboration to peer review and peer competition games. As shown by in the little big teacher model above, individual learning and group learning are not two distinct choices: the choice is rather when and how to alternate or interweave them and to study how they shape and reshape each other. Often, individual learning helps students acquire a preliminary understanding, basic mastery, and initial confidence regarding the task at hand, while group learning extends on this initial learning by generating, exploring, evaluating, and integrating multiple perspectives of the task.

The final remark is on two scenarios brought about by e-book-centered instruction: the library scenario and the playground scenario. If, for most of the classroom time, a class engages in e-book-centered instruction, then the classroom is sometimes as silent as a library, yet at times, it may be as noisy as a playground. Individual learning leads to the library scenario, of course. Even when a teacher is too busy to help a student in need, a system can locate a fellow classmate who can help (Hoppe 1995; Ikeda et al. 1997; Vassileva et al. 2003); these two students can communicate silently through the network, thereby maintaining the quiet atmosphere of a library. Actually, even for some small group learning projects, if group members communicate silently through the network, such learning remains within the realm of the library scenario. For other group learning models such as the class game EduBingo, students yell out 'Bingo' loudly from time to time. In most competition learning games, including the little big teacher model, the classroom will be noisy, as students become thrilled by the exciting atmosphere. Quiet or noisy, in e-book-centered instruction, the classroom will not be dominated by the teacher's voice.

\section{Conjecture 5: Teachers increasingly become mentors}

What differences arise from acting as a mentor for each student in a class instead of a teacher? Being a student's mentor requires time, attention, and energy. Mentoring gives importance to one-to-one personal relationships. Being every student's mentor in a class of thirty students means being thirty mentors. Building thirty one-to-one mentor-mentee relationships is an extremely demanding, if not impossible, task. The teacher who performs the basic job of teaching develops only a one-to-many relationship with the class. A great teacher, but not an ordinary teacher, however, can go beyond this basic job, being every student's 
mentor. Great teachers are few and far between.

Being every student's mentor will become an overt mission for teachers in the digital classroom age. How can teachers be best supported then? First, the teachers' time in the classroom must be released from teaching knowledge-related content directly. Such direct teaching takes the form of teacher-led exposition or lecturing, as many Asian teachers do today - such lecturing occupies most of their time. This job should be significantly taken over by e-books or by e-book mediated group learning in the classroom. According to our experiments, e-books, through being able to provide immediate feedback, can do a good job of engaging students in the learning of mathematics concepts, and the teacher's role becomes one of monitoring and advising those students with particular needs. Also, since e-books can perform many of the routine or mechanical jobs of basic grading and analyzing grades, this can further save the teacher's time.

Second, to be a good mentor, the teacher needs a comprehensive student learning portfolio for every student. With these portfolios as a basis, the teacher can monitor, assess, and judge what to do with particular students, as well as determine what to speak about with them (and with their parents after class). Fortunately, when learning with an e-book, each student's actions can be collected as data that, as time goes by, accumulates and forms an extensive portfolio for that student, which must be safeguarded to ensure privacy. With extensive portfolios and effective portfolio-analyzing tools, digital classroom teachers will have a better chance of becoming great teachers. For Chinese, being a teacher means being associated with Confucius to a certain degree, such that they are expected to possess some of the attributes of Confucius. Confucius was a great teacher not only because the content of his teaching was influential, but also because he served as a personal mentor to all his students.

Last but not least, in the digital classroom, with safeguarded and comprehensive portfolios for each student, teachers can better protect and maintain student confidence (Cheng et al. 2009). One may imagine how often students hear in their classrooms words such as 'high' and 'low', 'good' and 'bad', 'fast' and 'slow', 'beautiful' and 'ugly', and so forth. Actually, in both spoken or written English language, the frequency of appearance of adjectives make up about 10 percent of all main parts of speech (Biber et al. 1999). This means that for every 10 spoken words, students are likely to hear one adjective, reinforcing the fact that we are indeed living in a world of social comparisons. Even very young children are sensitive to social comparisons. But, for years students have been put together in a 
social place called a classroom. For years they have been comparing themselves to each other, intentionally or unintentionally. For years such social comparisons have affected their social status and self-confidence.

If this has been inevitable in the traditional classroom, then in the digital classroom the teacher will retain some control over what, how and when to release or to withhold student portfolios. In other words, constructive use of student portfolios can provide support for the teacher as they help students establish their self-confidence. In turn, this self-confidence will affect their self-concept, and thereby their social status in the class. One day, teachers in digital classrooms will speak of classroom equity.

\section{Story 3: A conversation with my high school teacher}

In 2007, I received a message from the $\mathrm{G} 1: 1$ forum $^{1}$ regarding a news report from the Washington Post:

"Educational software, a \$2 billion-a-year industry that has become the darling of school systems across the country, has no significant impact on student performance, according to a study by the U.S. Department of Education..."

The news reminded me a conversation with my high school teacher. A year later that conversation came to my mind again when I participated an annual meeting of the USA-Taiwan governments funding agents. I attended the meeting to respond to a 2008 Cyber Learning Report (Borgman et al., 2008) composed by a group of US experts:

"...Few of the innovations tried over the ensuing 25 years have resulted in large-scale systemic change in education. Despite the revolutions wrought by technology in medicine, engineering, communications, and many other fields, the classrooms, textbooks, and lectures of today are little different than those of our parents. Yet today's students use computers, mobile telephones, and other portable technical devices regularly for almost every form of communication except learning..."

Here is my short story. In high school, I worked hard on mathematics, sometimes working at university level problems until two or three o'clock in the morning. In

\footnotetext{
${ }^{1}$ http://www.g1 to1.org/
} 
a public examination, however, my results were not good, far away from my expectation. I said to my mathematics teacher, 'You know I can do much harder problems than those in the examination. But I just could not have got a good result. Examinations are unfair!' His response was a surprise. He said, 'Well, you can complain about examination, but if you haven't done a good job yourself to meet the examination challenges, society will not listen to you.' After about 40 years, I still remember every word he said. My teacher knew how hard I had been working, and I expected something to comfort me. In the end, I learned that before we complain, we first must ask ourselves whether we have done something good enough that our audience can trust us and listen to our complaints.

The Washington Post story illustrates that society has an expectation - that researchers and practitioners must improve student academic achievement through technology. The 2009 Report reflects unfulfilled expectations of technology adoption in classrooms. Evidently, there is an analogy between the conversation with my teacher and the two reports mentioned above: I am analogous to the researchers and practitioners of our field; the public mathematics examination I took corresponds to society's examinations for researchers and practitioners-improving student academic achievement through technology and adopting technology in the classroom; the poor outcome of my mathematics examination matches to the poor outcomes for learning improvement and technology adoption thus far.

We can of course explain the outcomes thus far. Despite the enormous potential of the Internet in supporting learning, its impact is still peripheral to the classroom - the core place of formal education. Furthermore, the digital classroom wave has only just arrived; digital classroom experimentation is in its infancy.

However, I see a brighter future for digital classrooms arising from research. That said, society gives researchers like us an examination: the resolving of the all-up-to problem, the mobility problem, and the productivity problem in the next 10 years.

\section{Conjecture 6: the 'all-up-to' and the 'mobility' problems will be resolved in 10 years}

The greatest achievement made in formal education since the Industrial Revolution has been the pervasive accessibility of basic education, but the greatest failure has been the large number of 'dropouts'. It is the law in many 
countries that elementary or secondary students cannot drop out of school. So what we mean here refers to those students who have developed a self-concept that they are the losers of a class. The major reason for this feeling of failure is that a small portion of students consistently receives the lowest scores in academic subjects, constantly weakening their confidence and interest. This is the most inhumane part of classroom learning. From my perspective, this unfortunate fact primarily arises from limitations in the old medium of traditional classrooms, including blackboards and chalk, textbooks and workbooks, and pens and pencils. The new medium in digital classrooms, however, offers us the opportunity to resolve two pressing problems: the all-up-to problem and the mobility problem. This should significantly reduce the number of dropouts.

The all-up-to problem is that almost all students in a class can live up to the level of academic achievement required by the standard curriculum. Tactically, if we assume that the majority of students in the class can meet and exceed these requirements, but that the slowest sixth may not, then resolving this problem lies in an individualization of instruction for the slowest sixth in the class - only individualization can help these slower students catch up. Furthermore, when the digital classrooms empower teachers to become an individual mentor for each of these students, individualization can be more effective and humane. For tactical reasons, I call this the 'first one-sixth problem'. That success in this problem can be accomplished through individualization and will be elaborated later as Bloom's challenge.

The mobility problem merits some explanation too. Let us assume that at the beginning of an academic year, students in a class can be evenly divided into three groups (each group is one third of the class) - the slow, the medium, and the fast - according to their previous academic achievements. Then, after one year, half of the students from each group (one sixth of the class) migrate to different groups. For example, half of the students in the slow group move to the medium group or the fast group; likewise, half of the students in the medium group move to the slow group or the fast group. The mobility of student academic achievement is a good indicator that, with respect to the class, every student can do better or worse. Therefore, everyone can strive to do better and be confident that it is possible to do so with determination and effort. Again, in the digital classroom, as discussed previously, an emphasis on individualization and the teacher-as-mentor can empower us in this challenge. Also, for tactical reasons, I call this the second one-sixth problem. 
In sum, the all-up-to problem concerns whether all students can reach the required achievement levels set out in the school curriculum, in particular, whether individualization can help slower students catch up; whereas the mobility problem maintains student self-confidence and belief that that everyone can excel if one is determined and works hard. Indirectly this will help students to be willing to stay in school. The productivity problem to be discussed in the next section conjectures whether there will be an overall leapfrog improvement in academic achievement for the whole class.

\section{Conjecture 7: Bloom's 2-sigma challenge: the productivity problem will be resolved in 10 years}

Bloom (1984) compared conventional learning of with about 30 students per teacher to that of experimental classes learning via one-to-one human tutoring (Bloom 1980). Achievement measures were striking: experimental classes outperformed conventional ones by two standard deviations (the two-sigma effect). In terms of students' achievement variation, about $90 \%$ of the tutored students reached a level of achievement attained by only the top $20 \%$ of those receiving conventional instruction.

Bloom's 2-sigma problem has long been a target of intelligent tutoring system research providing a computerized form of one-to-one tutoring. This does not mean digital classrooms require a student's e-book to be an intelligent tutoring system. E-books allow various group learning and teacher-led instructions, in addition to individual learning. Moreover, research from our field has already provided many useful weapons for attacking the Bloom's problem. The emergence of digital classrooms signals that for years to come we will have a platform to exercise these weapons to confront Bloom's problem, proving that it is resolvable.

Further, two facets of Bloom's problem need to be distinguished for digital classrooms: the weak problem and the strong problem. Bloom's weak problem is the same as the original Bloom's challenge-improving student achievement. Except within in a digital classroom, and not just restricted to one-to-one human tutoring. To make the problem more practically useful for us in the future, we need to look at the strong problem, also called the Bloom's productivity problem, by adding two conditions.

The first condition is the teacher's effort. I speculate that many previous studies on innovative classroom pedagogies may have achieved improvements in learning, 
but that the majority has incurred a burden on the teacher. If we define 'lazy' as follows:

lazy $=>$ less effort regardless of better or worse outcomes,

then we can define 'intelligently lazy' as:

intelligently lazy $=>$ less effort but better outcomes

Not all people are lazy, but most desire the opportunity to be intelligently lazy. Making people intelligently lazy is the very essence of why people need technology. But no teacher wants to be labeled as either lazy or intelligently lazy. However, people do want to be productive. Thus, we may define:

productivity $=$ student output/teacher input

In other words, the productivity problem signifies an input-output problem, aiming to maximize output and minimize input. In this definition, teacher input refers to workload or effort. A teacher does not usually desire additional workload, nor may the teacher want less, unless already overloaded. Workload usually means time expended. Thus, adding this condition means that Bloom's productivity problem is identical to Bloom's original problem, except for the fact that teacher workload or time spent in the digital classroom does not exceed that of the traditional classroom.

The second condition is the time duration of the experiment. Each experiment carried out by Bloom's team studied one subject for three weeks. To resolve Bloom's strong problem, I propose that an experiment should study one subject for a period of at least one academic year. Further, the experiment should not only pertain to learning in the classroom, but also extend to include homework assignments (i.e. students can take their e-books home). If an experiment is limited to a short period, researchers may be tempted to change variables in the environment to ensure the validity of their results. This will make it difficult to evaluate whether the experiment integrates well with normal classroom practices. However, even if we limit our study to one subject over a period of a full academic year, we will need to develop material sufficient to match the curriculum requirements for that subject, meaning that for the strong Bloom's problem, an entire research team will be needed. 


\section{Remarks}

There are two remarks on the definition of 'productivity'. First, student output, in addition to academic achievement measures, can include other pertinent items such as interest and self-confidence. Second, if teacher input becomes substantially less, teachers have more time for higher level tasks such as analyzing statistics on students' performance that can lead to appropriate programme adjustments, and helping those students who need immediate attention, rather than spending time on lower level tasks. In this illustration of Bloom's productivity problem, the student input means their measure of achievement.

\section{Conjecture 8: one-order increase of learning tasks is possible}

In this and the next section, I offer reasons why the Bloom's productivity problem can be resolved through digital classroom experiments. The first reason is the increase of time-on-task. For instance, in traditional classrooms it can take several minutes for the teacher to distribute handouts. In a digital classroom, this is all done instantly with the click of a key. Similarly, switching from one activity to another can also be done swiftly. This first reason, increasing time on task, is minor compared to the next three.

The second reason is that engaging learning tasks can help to assure that we resolve Bloom's productivity problem. In our experimental classes, when we adopt a game-based learning pedagogy, the design of engaging learning tasks means that students spend time on the tasks without losing interest. For example, in Taiwan, elementary students are required to practice mathematics a great deal. So, many lose their interest in it. In fact, Taiwan was the top country in a recent international junior high school mathematics achievement evaluation (OECD 2007), but Taiwan is almost the bottom country in terms of students' self-reported interest in the subject. Researchers can, however, design learning games that let a student catch a fish, for instance, and score some points if the student can correctly compute an arithmetic expression. The student then has a clear goal- to win the game by catching fish. It is interesting to note that a student's goal for the task may not be the same as the designer's learning goal-to have students practice arithmetic - which is embedded in the task. Because of this departure from the students' goal by the designer's learning goal, the student can continue practicing without losing their interest in mathematics. Perhaps practicing arithmetic computations are simple tasks when compared with solving difficult mathematics problems or writing a composition. For such complex tasks, students, however, may engage in social games such as peer review or group competitions. 
Students want goals because they want challenges, challenges that they can overcome by exerting effort. Challenges, whether through gaming or learning, can engage student interest as long as students can overcome them one by one. Challenges remain effective for students as long as the challenges get more complex and more difficult, while students can still overcome them by practicing more or by acquiring new skills. Individualization and the portfolio play a role here, because whether a task is challenging or not depends on the student's past experience (Crawford 1984; Csíkszentmihályi 1990; Rouse 2004).

Bold and problematic, the one-order-increase conjecture is based on my observations of game-based learning experiments. It declares that we can design a sufficient volume of engaging learning tasks for students such that they become able, both in the classroom and at home, to finish 10 times as many learning tasks as they can complete by the current practice in school, within the same amount of time. Since these are engaging and challenging tasks, students will not lose interest in the subject.

Even though we can design so many such tasks and students can learn to finish them does not mean that we have to do this. If we believe that practice makes perfect, then a sure way to increase achievement measure by two-sigma (two standard deviations) is to have students do a tremendous number of exercises: we can use this method to accomplish this without students losing inertest in the subject. Whether or not researchers are interested in proving or disproving the conjecture, I do not recommend having students do this much work. As mentioned earlier, the total amount of homework assigned is demanding for Taiwanese students. Therefore, another implication when the conjecture is proved is that the students may not need to spend so much time doing homework. It is possible that an increase of twice the amount of learning tasks will suffice. Finally, and different from other conjectures, this conjecture mainly supports the second reason that Bloom's productivity problem can be resolved.

\section{Conjecture 9: learning-by-teaching will become more prevalent}

This is the third reason why Bloom's productivity problem will be resolved. When we speak of core classroom pedagogical models for deep and complex learning, most likely we relate them to inquiry-based learning, collaborative learning, reflective learning, group competition games, and multimedia story telling, among others. Learning-by-teaching, interestingly, captures most elements of these models, and we are unlikely to find any other current model more 
thorough. For example, the little big teacher model covers the following: learning about the material which means learning and re-learning to ensure full understanding of the materials; searching for supplementary material on the web; composing teaching materials by designing and constructing expository exercises, problems, questions, and answers; negotiating with peers when synthesizing their different constructed lectures into one; and conducting face-to-face classroom instruction through verbal expository instruction, demonstrations, explanations, and asking or answering questions.

In the cognitive domain, learning-by-teaching does not only involve comprehending, but also synthesizing, questioning, explaining, analyzing, and evaluating. In the affective domain, learning-by-teaching develops a sense of ownership: both in learning and of the knowledge acquired. For example, it will foster a sense of mathematics of a student's own, science of a student's own, and so forth. This brings learning within reach, thereby building stronger self-confidence, making learning appear in a more positive manner, and increasing joy in achievement. Thus, if a one-order-increase of the learning task conjecture ensures learning after extensive practice, then learning-by-teaching makes certain that learning is high quality. Both substantially contribute to resolving Bloom's productivity problem.

Furthermore, digital classroom settings encourage learning-by-teaching, as seen from the little big teacher model. In addition, there are other simpler forms of learning-by-teaching such as peer tutoring, peer reviewing, learning-by-teaching a virtual character (Leelawong \& Biswas 2008), and so forth.

The learning-by-teaching model will become prevalent in digital classrooms because, besides encompassing elements of contemporary pedagogical models, it has been well practiced in schools. The participants, however, switch: it is the students who do learning-by-teaching, not the teachers (note that teachers also learn by teaching; when they teach, they learn).

\section{Story 4: a 13 year old teacher}

This story is a supplement to the previous conjecture. "Ah-Chung", a 13 year old student, won an online teacher contest in EduCity in 2000 (Young et al. 2002). He taught an online course about Visual Basic to more than 10 students. These students did not know that their online teacher was a boy who was younger than all of them. In his testimony at the award, Ah-Chung told why he had taken part in the contest. He said prior to the contest, he participated in a science contest. A 
referee, who was a teacher, did not believe his work he presented, in which he used Visual Basic, was done by him. The referee suspected Ah-Chung's parents. After this failure, Ah-Chung then took part in an online EduCity contest, imaging that this teacher referee would be one of his students.

Ah-Chung is brilliant. However, his story indicates that many teachers do not believe their students. His story and the little big teacher model illustrate that the digital classroom will be much more liberal than most current classrooms and what most teachers think today, provided that they can trust their students.

The fourth and final reason that Bloom's productivity problem will be resolved is that the teacher will serve as mentors for each student. These four reasons lead me to believe that researchers will resolve the problem with some compelling digital classroom experiments within the next 10 years. More specifically, it will likely be resolved incrementally as the problem itself induces a series of benchmarks of student achievement measurement improvements, moving towards the $2 \sigma$.

\section{Conjecture 10: digital classrooms will evolve from pursuing individualization and productivity to pursuing personalization and global citizenship}

Before proceeding further a short summary of what have discussed thus far may be helpful. For elementary schools in Taiwan, and perhaps to some extent for schools in some East Asian countries, I have depicted a possible trajectory of classroom evolution affected by digital technology in a series of conjectures. The arrival of the digital classroom wave (Conjecture 1) because of increased availability of e-books and e-boards signals a great change occurring over the next 20 years (Conjecture 2). This great change is the main conjecture, supported by the following eight. The prevalence of e-book-centered instruction (Conjecture 3 ) indicates that teaching and how the entire curriculum is integrated into the repertoire of classroom activities will be completely different. Such a transformation will dramatically change the teacher's classroom role-teachers will become mentors (Conjecture 5). The emphasis on individualization (Conjecture 4) will allow better instruction for slower students, which in turn helps resolve the all-up-to and mobility problems; that is, every student can meet the level of academic achievement demanded by the current school curriculum, and not develop any negative self-concept (Conjecture 6). The endeavor to resolve the Bloom's productivity problem (Conjecture 7) will take us much further, suggesting that it is possible to leapfrog student academic achievement without imposing any additional workload on the teacher. Both the 
one-order-increase (Conjecture 8) and the prevalence of learning-by-teaching (Conjecture 9) ensure that Bloom's problem can be resolved. The significance of overcoming these problems goes far beyond passing the examinations that society places before us. Society is thrilled by leapfrog improvements and forced to rethink vigorously future educational goals.

When these problems have been resolved, we reach a crossroad towards digital classroom evolution. At that point, the digital classroom will face three choices: (1) boosting academic performance on standard tests, much further than that by other traditional classes; (2) leapfrogging the class curriculum to that of a senior grade, and (3) enabling the class to explore other learning opportunities after the basic requirements and standard tests are completed. The first choice does not just target substantial academic improvement; it aims at super improvement. If, however, student achievement in basic subjects (such as reading, writing, and mathematics) can meet or even moderately exceed society's expectations, the class does not need to pursue a huge leap of improvement. Sports are good, but everyone who runs 100 meters does not need to finish within 10 seconds. The second choice is dangerous: endless and needless, such pursuit students slave away all their time. The third choice, however, allows students to explore what educational researchers have long been dreaming of.

If digital classrooms opt for this third choice, then they will afford two liberations: the teacher liberated from transferring knowledge through teacher-centered instruction, and students liberated from working hard to live up to the level required by the curriculum, because they will be able to achieve this goal without requiring so much time and effort. Opting for the third choice will allow the digital classroom evolution to attain the second stage-the pursuit of personalization and global citizenship. In other words, according to the productivity definition, if we do not endlessly aim at high achievement measurements for student output, and when teachers can substantially reduce workload, then both teacher and student will be liberated and free to pursue other more meaningful and important educational goals.

Most of what students learn nowadays is decided by education policy makers and curriculum designers. In contrast, personalization encourages that a portion of what students learn is from their own choices. Building on students' diverse personal strengths, interests, and needs, personalization enables students to reach their full potential and have support for the establishment of personal niches or expertise in different domains. The traditional curriculum is breadth-first learning: 
students learn different subjects but learning just a bit about a subject before switching to another subject for learning another bit. In contrast, personalized learning is depth-first: students learn about a subject of interest in depth and, if problems or obstacles arise, the student sidetracks to learn some other subject in order to resolve their problems. For example, if a student has a passion for robots, the student may spend a lot of time building one. When that same student encounters a problem that requires computer programming or mathematics, the student may then learn about computer programming or related mathematics concepts, finally returning to build the robot. In learning about computer programming or mathematics, the student has a purpose - to solve the problem at hand. Personalization will shape the educational system around student interests and abilities.

My view on personalization is based on anticipating that technology enhanced learning will one day allow us to pursue this goal. This topic has recently generated discussions in the United Kingdom. ${ }^{2}$ Personalization is a natural goal to pursue, but it is not a realistic goal if individualization and productivity (and hence technology adoption in classrooms) has not succeeded to some degree. Personalization is always a good research topic. It, however, will be a 'great leap forward' if it is put into practice on a large scale now.

In addition to the pursuit of this personalization, the global warming crisis has spurred global citizenship as an educational concern. Global citizenship means that we extend our local interests such as love of family to global interest: it challenges us to recognize and strive for universal equality, world peace, and global environmental protection, among other aspirations. Students in the digital era can and should build foundations for a better world by bettering oneself, nurturing a caring family, incubating a humane society, and fostering a peaceful and collaborative world - as said by Confucius (in the book Da-Hseh). To foster global citizenship in students, 'personalized online classes' on various global citizenship topics represent the best platform.

Interestingly, if e-books and e-boards are now preparing us for individualization and productivity, then the Internet upsurge has already prepared us for personalization and global citizenship. The link between the Internet world and the classroom world (Fig 2) marks the transition (or merging) of two different paths of pursuits. Furthermore, harnessing popular handheld devices owned by

\footnotetext{
${ }^{2}$ http://nationalstrategies.standards.dcsf.gov.uk/node/83151?uc=force_uj
} 
students will create personalized outdoor learning environments. Personalization and global citizenship may even be regarded as forms of an extra curriculum or informal learning. As serious assessment via personal learning portfolios captured by e-books develops, this extra curriculum or informal learning may eventually become a part of the formal curriculum.

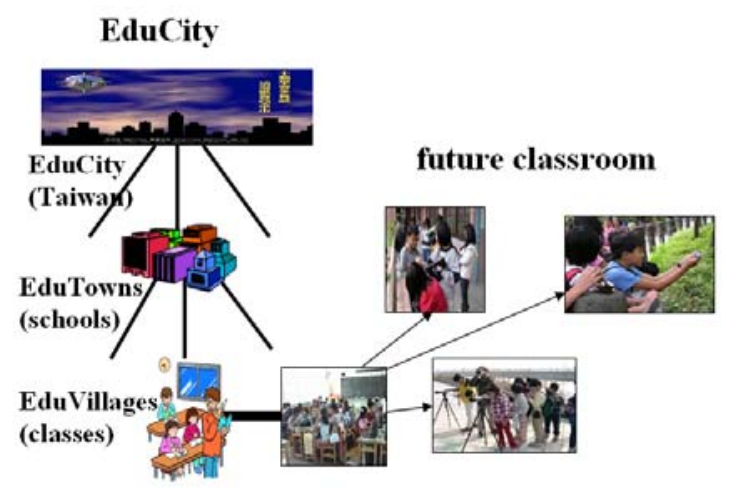

Fig 2 Linking the Internet and the classroom worlds

Actually, the transition from the first stage (the pursuit of individualization and productivity) to the second stage (the pursuit of personalization and global citizenship) announces the departure of the old era of formal education-classrooms enabled by blackboards and chalk, paper textbooks and workbooks - and the arrival of the new era of formal education in the digital world - classrooms enabled by e-books and e-boards. In reality, the endeavor for these two sets of pursuits will likely take place simultaneously. However, only when we truly leave the first stage can teachers and students be truly liberated from the aforementioned constraints imposed by the traditional classroom. In this way, vigorous exploration of a universe of new possibilities for the new era of education can begin. In this new universe, the differences between learning, gaming, and working may blur-learning in schools may resemble working in an adult society. Students may often go to and fro between two levels of activities: the game worlds and the content games. The game worlds will consist of multiple online games where students reside for years, seeking for what they think precious to them - self-confidence, self-identity, social statuses, and more-which they cannot easily find in the real world. All the content material in the current paper textbooks will be completely redesigned as content games; their design will depend on the pedagogical nature of different subjects. The content games will be 'packaged' in different ways to relate to different game worlds, leading students to engage in these two levels of activities.

\section{Story 5: secrets you cannot tell}


The classroom reform delineated so far may only be a rainbow if we do not recognize the difficulties in real world practice. Ma, a scholar originally from China, conducted research comparing elementary school mathematics teachers in the USA and China. She discovered that a substantial percentage of USA teachers are unable to compute or explain correctly certain computation processes for some arithmetic expressions. Her book on this study is well known (Ma 1999). I suspect that this phenomenon has been around for generations of teachers, and many teachers and researchers have known about it. Nevertheless little change had occurred in the USA until a comparison study from elsewhere, China, sobered the mathematics education community of the USA.

A similar phenomenon occurs in Taiwan pertaining to elementary Chinese language teaching. Too much class time is spent on recognizing Chinese characters and composing sentences. Furthermore, Taiwanese elementary students study only one short article from their textbooks every week: this is the same for elementary schools in Hong Kong and mainland China. But if the pedagogy changed, students could read a dozen more articles each week (He 2004). Another surprise to me is the immoderate number of mistakes in Chinese language textbooks. The fact that such unprofessional textbooks have been around for many years is puzzling. I hope that another $\mathrm{Ma}-\mathrm{a}$ researcher from the West-writes a book on this topic.

For elementary mathematic in Taiwan, in addition to the large gap discussed above (the fastest third of the class is four times faster than the slowest sixth of the class), the difficulty level of textbooks is roughly aimed at the level of the slowest third of the class. This means that the other two-thirds of the class should be using more advanced textbooks.

As such, the goal of an experimental site is to bypass all these unreasonable phenomena embedded in the institutional contexts or school culture by intelligently establishing new pedagogies with the new medium (e-books and e-boards). Teachers must also be retrained through professional development in order to put these new pedagogies into practices.

\section{Story 6: Deng's economy reform and its parallels with digital classroom reform}

I suspect that the educational software mentioned in the Washington Post news story would not fit into classroom use; that is, it is likely de-contextualized from classroom practice. Also, there is, as of yet, no sign of any vast dissemination of 
digital classroom practice. However, I believe that the experience of the economic reform under Deng Xiaoping (Marti 2002), a former leader of China, can shed light on how to start digital classroom reform.

Deng launched economic reform in China in the late 1970s. Learning from the disaster of the 'great leap forward' in the 1950s instituted by Mao Zedong, Deng understood that successful reform requires decades. Rather than starting with a countrywide reform movement, Deng chose experimental sites, called Special Economic Zones (SEZs), as the locomotives to drive reform. For example, in 1979, Shenzhen, a fishing village situated next to Hong Kong was chosen to be the first SEZ in order to learn and practice the capitalism from Hong Kong, a prosperous British colony then. These SEZs were a huge success. Today, while these SEZs' successful experiences are being duplicated in other cities, these SEZs are enjoying the outcome of the reform - economic prosperity - and they continue to accumulate and expand their successes.

The rationale of the SEZ approach is simple: the scale of an SEZ is sufficiently small that drawbacks can be fixed before they spread too far. Once drawbacks have been reduced or backfiring has been prevented, the successful experiences can be reinforced and the failure experiences can be avoided, further amplifying the chance of success. SEZs take time to develop, and this is a seeming disadvantage. But Deng did many other things while he waited for the results of the SEZs. He educated his people about the reform and ensured a stable political environment for preparing the future scaling up of the reform.

The reminder of this section explains Deng's strategies and how they parallel with those of digital classroom experimental sites. Deng's first strategy was to choose a productive problem to resolve, not a problematic problem. A productive problem is one that can have a good chance to be resolved successfully, and, once resolved, people benefit and also grow more confident to face the next challenge. A problematic problem, however, is one that, in the process of being resolved, creates more problems, making the original problem even harder to resolve. Thus, it is important to identify at the outset which problems are productive and which are problematic. Very often a productive problem is closely related to a problematic problem. In such a case, we strive to resolve the productive problem and by all means avoid tackling the related problematic problems. Once a productive problem has been resolved, related problematic problems is likely to lessen. 
When Deng initially dealt with the economic reform problem, he had to face a related problematic problem-reforming the political system. By inventing a theory called Socialism with Chinese Characteristics (showing that he was remaining true to socialism and not embracing Western capitalism) and by promoting the theory throughout the country, Deng avoided dealing with this problematic problem. Whether China's problem of political reform will lessen in the future is unknown. At least the political environment during the reform in the past was stable. In contrast, the former leader of the Soviet Union, Mikhail Gorbachev, chose to tackle both economic and political reforms at the same time. He failed.

While running digital classroom experimental sites, problems will continually emerge. Identifying which are productive and which are problematic will be paramount. In addition to improving students' academic performance, how to ease the teacher's daily burden is a productive problem. For example, automatic grading and analysis of students' class work or homework assignment can contribute to reducing the teacher workload. Putting e-boards into classrooms is also productive; compared with blackboards and chalks, e-boards allow teachers to become more animating.

The second strategy is to make the experimental sites special. The SEZs were special because the government allowed them to have different policies. Old policies may empower the old ways, but constrain the changes for the new ways. If those running an experimental site must completely follow the old policies without any flexibility for re-adjustment, change becomes almost impossible. Digital classroom experimental sites are also special because they need special administrative support and flexibility sufficient to allow for success of experiments within the capacity permitted by the policy of education governance.

The third strategy is to preach. In the early stage, aside from creating the theory of Socialism with Chinese Characteristics, Deng developed another theory-'Seeking truth from facts'. This theory came with his famous quotation: 'I don't care if it's a white cat or a black cat. It's a good cat so long as it catches mice.' And, in later stages, to unleash a wave of personal entrepreneurship, he coined another catchphrase 'To get rich is glorious.' Also, he reiterated the phase: 'Some areas must get rich before other areas,' to assert the faster development of the coastal regions. Preaching not only educates people to prepare them psychologically for forthcoming changes, but also legitimates the changes. 
Many teachers in Taiwan consider themselves to be the queens or kings of the classroom. Even in a traditional classroom, there might be 'power struggle' between who is controlling the classroom: the teacher, or the noisy students conducting group learning. A similar phenomenon may happen in a digital classroom, for who will draw the class's attention more- the teacher or the e-books - when the frequent use of e-books addresses individualization. Thus, for the process of bringing individual learning into the classroom for a designated portion of classroom time, we may start by advocating the importance of individualization. The strategy must be to preach more but do less, and then gradually increases the amount of classroom time for individual learning until we reach our designated portion of time.

Preaching not only legitimates what we want teachers to change but also sets up goals and missions for them and therefore, creates a demand for increased use of e-books. For example, as e-books begin to assume a portion of the in-class teaching job for teachers (we should never mention that e-books will replace teachers), we give the teacher a new mission-becoming a mentor to each student - and suggest that the teacher pay more attention to slower students. Only in this way can the teacher elevate the performance of the slower learning students to a point where they can all live up to the requirements set out in the curriculum. To meet the new demand created by this new mission of mentorship, teachers will begin to see that e-books can share their load; that is, they will seek and use e-books more. Following further evidence of success, teachers will be encouraged to take on other challenges-productivity, personalization, global citizenship — stepping up the demands for e-book usage; eventually, e-books will become indispensible in the classroom.

The final strategy is to ensure an extended experimentation period. In his famous 1992 Southern Tour, 13 years after 1979, Deng proclaimed the success of Shenzhen, the first SEZ. In total, Shenzhen had taken 30 years to evolve from a small fishing village into one of the most prosperous cities of China today, with a population of 14 million. This will be the same for digital classroom experimental sites: they require years of experimentation, tumbling in the beginning stage but flourishing exponentially in the later stages. This strategy seems to be obvious, but it is the most difficult for many policy makers to adhere to, who simply invest vast sums and expect success within a few years. They cannot wait. Table 1 below summarizes the parallels between the two reforms.

Table 1. Summary of the parallels of strategies between two reforms 


\begin{tabular}{|l|l|l|}
\hline Strategies & $\begin{array}{l}\text { Deng's Economic } \\
\text { Reform }\end{array}$ & $\begin{array}{l}\text { Digital Classroom } \\
\text { Reform }\end{array}$ \\
\hline $\begin{array}{l}\text { 1. Choosing a productive } \\
\text { problem and avoiding } \\
\text { problematic problems }\end{array}$ & $\begin{array}{l}\text { e.g. Avoiding political } \\
\text { reform problem }\end{array}$ & $\begin{array}{l}\text { e.g. Avoiding adding } \\
\text { teachers' workload }\end{array}$ \\
\hline $\begin{array}{l}\text { 2. Setting up } \\
\text { experimental sites }\end{array}$ & $\begin{array}{l}\text { Setting up Special } \\
\text { Economic Zones such as } \\
\text { Shenzhen }\end{array}$ & $\begin{array}{l}\text { Setting up digital } \\
\text { classroom experimental } \\
\text { sites }\end{array}$ \\
\hline $\begin{array}{l}\text { 3. Preaching (and } \\
\text { sometimes doing less) for } \\
\text { setting up goals, } \\
\text { legitimating the process, } \\
\text { and stepping up demand }\end{array}$ & $\begin{array}{l}\text { e.g. Advocating } \\
\text { "Socialism with Chinese } \\
\text { legitimating free-market } \\
\text { policy); advocating “to } \\
\text { get rich is glorious" later }\end{array}$ & $\begin{array}{l}\text { e.g. Advocating } \\
\text { individualization and } \\
\text { group learning (instead of } \\
\text { teacher-centered } \\
\text { learning); advocating } \\
\text { one-sigma productivity } \\
\text { later }\end{array}$ \\
\hline $\begin{array}{l}\text { 4. Experimenting with } \\
\text { ample time, 10 years at } \\
\text { least (sustainable }= \\
\text { disseminable) }\end{array}$ & $\begin{array}{l}\text { Having enough time to } \\
\text { fix mistakes and } \\
\text { accumulate successes } \\
\text { before dissemination }\end{array}$ & \begin{tabular}{l} 
Same reasons \\
\hline
\end{tabular}
\end{tabular}

Regarding the dissemination of experimental sites, there are three questions: when, where, and how. In terms of 'when' we must understand that being sustainable is equivalent to being disseminable. Unless an experimental digital classroom site is able to sustain change itself, its models and operations cannot be duplicated (we should note that many researchers in our field are only interested in novel findings in digital classrooms, and the experimental periods are so short that sustainability is not their concern). There are two indicators (or conditions) for the sustainability of an experimental site. The first indicator concerns attaining productivity to some degree, for example, a one-sigma productivity improvement (the average final achievement measurement of the students in the experimental digital classrooms is above $84 \%$ of those in the traditional classrooms). The second indicator is that the site itself enjoys a steady process of accumulating successes through expansion. For example, upon attaining the initial productivity, the school is encouraged to expand the number of digital classrooms, from one class to the entire grade, from one grade to all grades, from one subject to all subjects. Thus, similar to an SEZ in China, when initial economic successes emerge, it will expand itself and look forward to additional growth. 
Next, let us consider the 'where' question: to where (to which schools) does a disseminable experimental site disseminate its experience? The answer is actually quite straightforward: schools in the proximity of the experimental site. Being compared with something better, especially by 'seeing' the difference, provides a strong impetus for change. You have no excuse not to change, or for failure to change when there is a successful example sitting next by you. This explains why the first SEZ was located in the vicinity of Hong Kong. As for the 'how' question, fortunately there is already an enormous number of researchers and practitioners in the field of professional development, and large portions of associated methodologies can be adapted for this purpose. In fact, China took this same step: they developed various programs to train their officials such as sending them to visit SEZs and abroad, and arranging for them to take part in various workshops and courses.

With answers to all these questions, the reason why vast dissemination of digital classrooms has not yet come into view is that disseminable experimental sites are still rare, if they exist at all. Also teachers in the experimental sites must change their practice behavior. Change in behavior takes time, however. In most respects, it is simpler and faster to deploy hardware infrastructures than to change people's behavior. Both economic and educational activities involve complex human behavior. For digital classroom reform, there has already come a number of Maos, seeking digital classroom 'great leap forwards', and there will be more Maos coming along in the future; Dengs, however, should come from our research community.

\section{Summary}

A summary of the conjectures I pose will be useful. But I need a device: a classroom framework (see Fig $3 \& 4$ ) expanded from the one developed by John Self (1974), which was originally for a computer. In Figure 3, the 'why' component shows that our East Asian societies are still primarily concerned with the academic achievement of basic or cardinal subjects such as reading, writing, mathematics, and science. The 'how' component is a core set of pedagogical models commonly practiced in traditional classrooms: they are mainly teacher-led expositions and at times individual class work and group learning. The 'what' component is the curriculum realized by the printed materials in textbooks or teaching manuals. And the old, enabling medium consists of textbooks and blackboards. 


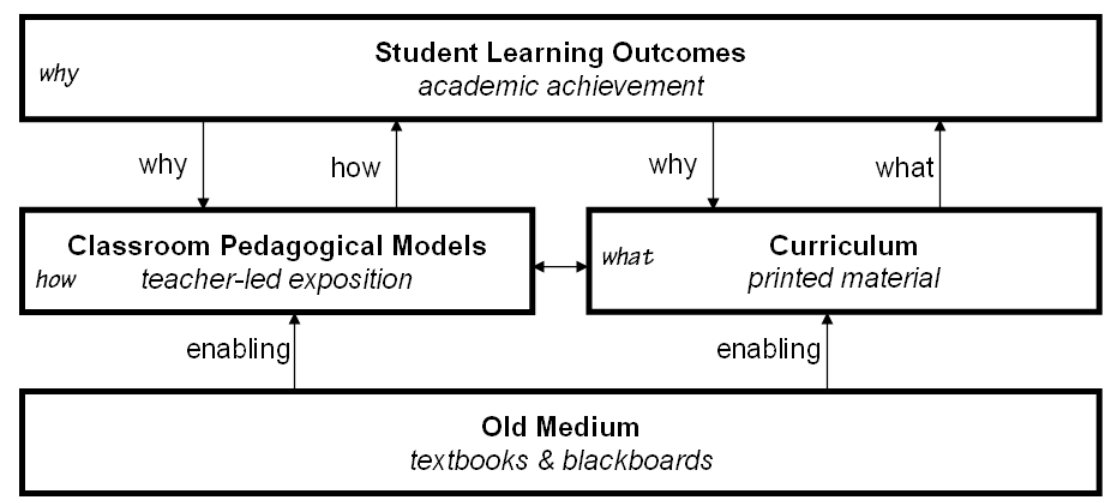

Fig 3 Self's Framework of Traditional Classroom

There are two ways of viewing Figure 3. The top down view is the 'why' view. It goes as follows: why students can attain academic achievement is, because there is a core set of well-adopted pedagogical models, which is usually called teaching and learning practices; and why teachers can practice these pedagogical models, is because they are enabled by the old medium. Another branch of the 'why' view goes similarly: why students can attain academic achievement, is because there is a curriculum of what to learn; why this curriculum with printed materials can be realized, is because it is enabled by the old classroom medium-textbooks and blackboards. The bottom up view is the 'enabling' view, which is similar to the why view but in opposite direction, starting from the enabling medium.

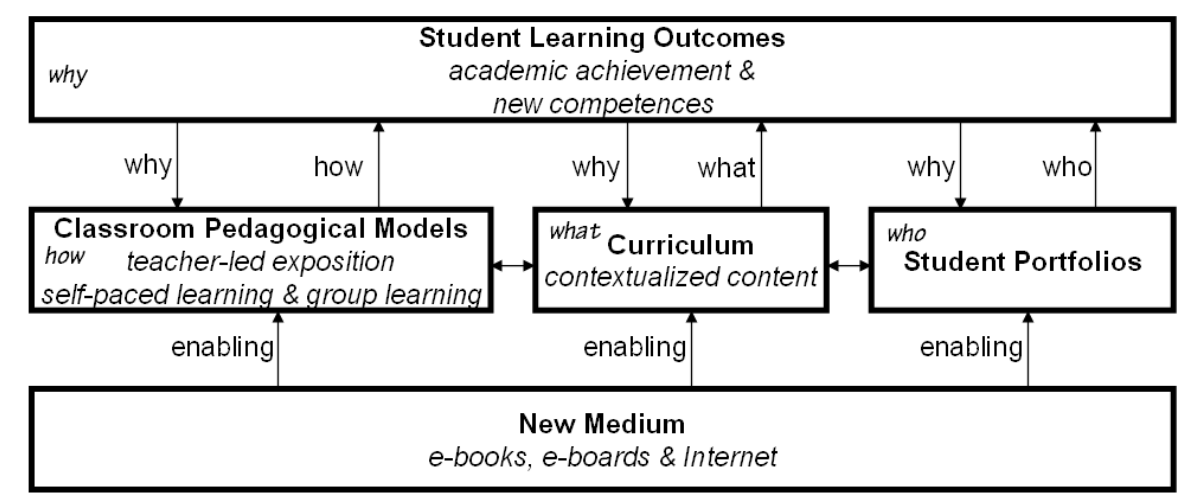

Fig 4 Self's Framework of Digital Classroom

With this framework, Conjecture 1 says that the technology availability of e-books for each student in the classroom (Chan et al, 2006), possibly with an e-board as well (the bottom layer in Fig 4), will be the source of change: changing of the enabling medium from textbooks and blackboards to e-books, e-boards and Internet. This change sets out the digital classroom wave. 
Conjecture 2 is an overall conjecture: there will be a great change of classrooms in the next 20 years. The change is radical because of the changes of the components in the middle layer: the core set of classroom pedagogical models, the curriculum with contextualized content (digital content material and software appropriate for supporting the new set of pedagogical models in the classroom), comprehensive and safeguarded student portfolios (with many analytical tools); as well as a change in the top layer: academic achievement improvement and fostering of the new competences needed for this century such as problem solving, creativity, teamwork, lifelong learning, among others. This overall conjecture is supported by the other eight conjectures.

Conjecture 3, Conjecture 4, and Conjecture 5 speak of the change in the middle layers: 'how', 'who', and 'what'. Conjecture 3 predicts that the e-boards are more welcome than e-books by teachers, and hence e-boards will be delivered to the classroom first. Furthermore, there will be a tension between the use of e-books and the use of e-boards, especially in East Asian countries where the teacher (and the teacher's voice) has a dominating role in the classroom. But the use of e-books prevails because there will be the gradual increase of demand of e-book use in the classroom. With the help of e-books on each student's hands and extensive student portfolios, Conjecture 4 postulates that individualization will be more and more emphasized in the classroom, not only in self-paced individual learning, but also in group learning. And therefore the dominance of teacher-led expositions will be lessened when self-paced individual and group learning increases. This also means that the whole curriculum will need to be completely redesigned with contextualized as digital. Because of Conjecture 4, Conjecture 5 points out that there is an important change of the role of the teacher-a mentor of each student - which is a much more demanding role.

Conjecture 6 to Conjecture 10 take the top down view: while addressing the 'why' component, the realization of these conjectures relies on the change of the components in the middle layer. On the top layer, there are two reasons why we have failed to meet the society's expectation. The learning technology oriented researchers are accustomed to view our field from bottom up: they concern how the design of new enabling medium for enabling changes of the components in the middle layer. They are less interested in the top layer, the 'why' component. The learning science oriented researchers are interested in taking a top down view. But there is a discrepancy between many learning science researchers and our society in terms of viewing the student learning outcomes in the top layer. Our society has not changed their primary view-their concern for the academic 
achievement in basic subjects - while many researchers are interested in the new competences demanded in this century. In fact, we need both, but academic achievement is more fundamental.

Conjecture 6 indicates that due to limitations of the old medium, teachers cannot ensure that every student can fulfill the achievement level required by the standard curriculum. If teachers allow e-books to share their teaching load, if teachers treat the e-books in the classroom as their teaching assistants enabling them to be better mentors for each student, and if teachers only need to focus on students of the slower-sixth of the class, assuming there will be overall improvement by the class (if Conjecture 7 is valid), then we can solve the all-up-to problem: every student can live up to the achievement requirement by the standard curriculum. Furthermore, to give hope to students that everyone can excel in academic achievement, if one is determined and make effort, we can even solve the mobility problem: mobility of students in the fast-third, medium-third, and the slow-third. Conjecture 7 is a bold conjecture: to convince our society with examples of enormous improvement in academic achievement-Bloom's 2-sigma productivity improvement. Conjecture 8 , the one-order-increase conjecture that harness game-based learning design for drill and practice types of learning tasks, is a supporting conjecture for Bloom's productivity conjecture. Conjecture 9, the prevalence of the learning-by-teaching pedagogical model, also serves as a supporting conjecture for Bloom's 2-sigma conjecture. Moreover, learning-by-teaching, on one hand, nurtures new competences because it incorporates many elements of contemporary pedagogical models; it, on the other, will become prevalent because the major part of it has been long been practiced in the classroom, but the role of the teacher is assumed by a group of students, further reinforcing the idea that knowledge acquisition will not need so much of traditional teacher-led expositions. But such teacher-led expositions can be performed as mini-lessons when needed.

Conjecture 10 is actually a conclusive conjecture. Even though in reality researchers and practitioners will pursue individualization, productivity, personalization, and global citizenship all together, there will be a big leap of change after a substantial realization of individualization and productivity, which represents the first stage of the change, to the second stage of change- the pursuing of personalization and global citizenship (the second stage may prefigure the need of school restructuring; see the final remarks in the final session). Compared to the relatively passive role of students in the quest for individualization, students take an active role in the pursuit of personalization: 
while the students are exploring potential aptitude in their domains of interest, the teacher and the curriculum, for example, accommodate students' individual initiatives. Furthermore, when we researchers talk about the new competences in this century, we should 'package' them from the students' perspective and have teachers help them pursue this personalization goal: developing their personal interest, expertise and niche in this collaborative yet competitive world, if the new enabling medium afford students spare time after fulfilling the academic achievement requirement. For global citizenship, it should be noted that it pertains to the 'what' component, aiming at diffusing this educational concern in every subject to learn.

In planning and taking actions, sometimes it is crucial to ask which component in the digital classroom framework is the most important. In terms of classroom change, the most important component is the core set of pedagogical models (how). This is because when the pedagogical models change, student learning outcomes (the upper layer) change; when the pedagogical models change, the contextualized content associated with the curriculum (what) change; when the pedagogical models and their contextualized content change, and when student data can be extensively collected by students' e-books (the lower layer), student portfolios (who) change. Thus, the change of the pedagogical models triggers a chain of changes. Also, if the set of pedagogical models is the 'skeleton', then contextualized content associated with the curriculum is the 'flesh'. If one asks: 'why digital technology is important to classroom learning?' The short answer to that question is that digital technology changes the way, the process how students learn. Nevertheless, when a new set of pedagogical models and their contextualized content are in place, in broadening and deepening individualization and personalization, student portfolios will gradually take a salient role. Thus, in terms of pursuing educational ideals, the most important component is the student portfolios. Actually, as time goes by, the student portfolios component is not only the 'memory'; it is also the 'brain' that impels further change of pedagogical models and their contextualized content. In sum, it is 'how to learn' that makes learning outcome different; it is the understanding of 'who to learn' that makes every student excel.

While the core set of pedagogical models, which includes how to learn and how to teach, is the key component in driving classroom changes, how to learn, however, is dependent on how to teach, which is hard to change. Therefore, if researchers can line up to form teams, and if research funding agents can support long-term research endeavor to establish experimental sites of digital classrooms, 
then we can start the classroom reform by school-based dissemination that adopts similar strategies used in Deng's economic reform of China.

\section{Final Remarks}

My research and the field in general reflect three orientations, orientating toward different goals and contributing in different ways. The first orientation is dream-based research (Chan et al. 2006), which relates to the design, development, and exploration of emerging technologies. My work on the learning companion and the networked learning classroom in the late-1980s and early-1990s was typical of this orientation. Another example is the researchers currently working on educational robots. As innovative digital technology continues to advance, this orientation continues to thrive as it generates more and newer possibilities for future learning. If dream-based research is more for the 'enabling' view as discussed above, then the second orientation, the adoption-based research, is more related to the 'why' view. Adoption-based research aims at proving the feasibility of spreading our research to real world practice, with the intention of impacting the existing educational system. Our research on EduCity and future classrooms are two examples of adoption-based research. The productivity problem described in this paper is another example: it incorporates existing technologies with other newly developed technologies in order to support pedagogies and corresponding learning materials, integrating them into the current curriculum, hopefully leading to desirable teaching and learning outcomes. The third orientation, humanity-based research, is even more from the why view. It is about the development of an individual's capacity almost entirely from that individual's perspective, as well as the cultivation of wellbeing of the globe as the learners' values. The earlier deliberations on individualization and personalization suggest a more thorough consideration of human nature in our future design of schooling, while the previous elaboration of global citizenship proposes that every student should care about the wellbeing of humankind-both of these relate to this orientation. As adoption-based research bears fruit, humanity-based research will flourish. By then we will notice that our education system can be more humane and more likely to meet future global challenges.

This paper depicts the landscape of changes to the classroom from the present to the year 2030 based on my experience working with schools in Taiwan. Those who are thrilled by technological innovations will say that the anticipation of these types of changes will be difficult. In the history of education, however, 20 years is relatively short - for even 100 years is short. In a 2007 keynote speech at a conference, I boldly 'elicited' four problems for researchers to resolve this 
century. The four problems included the productivity problem, which is about the performance or output/input problem; the school restructuring problem, which is how schools are being transformed; the personalized curriculum problem, which is the extension of intelligent tutoring system research's Holy Grail problem; and the global educational goal problem, which calls for a rethinking of educational goals from the global perspective. In this paper I elaborate in detail on the first problem - the productivity problem. I have not touched upon the second problem, the school restructuring problem, which will be tackled after the productivity problem has been resolved. It must be noted that the school restructuring problem is a problematic problem if the timing of resolving it not right. Yet, if the timing is right, which means that the pursuits of personalization and global citizenship have attained substantial success, and that school restructuring is needed to further these pursuits, then school restructuring will evolve gracefully. I slightly touch on the third problem - the personalized curriculum problem - which is related to personalization as discussed above. Personalization could serve as an engine for propelling a personalized curriculum. I also slightly touch on the final problem - the global educational goal problem - in the discussion of the pursuit of global citizenship. Moreover, this final problem is not final in terms of time order, but urgent. It demands a global, collective endeavor.

Here I give a slight account of the third problem. We can foresee at least two clusters of scenarios that school restructuring will lead to. School of their own is one cluster-teaching will be mainly performed by peers; elder students will mentor the younger students; classrooms of 30 students will be very few; and cross-age interactions will be as frequent as same-age interactions. School as embryo society is another - a school becomes more like a village and everyone knows each other to some degree; academic matters but so do the activities that make up daily life; schools are closely networked to form knowledge building societies (Scardamalia \& Bereiter 2003); learning, gaming and work (similar to the adults' world) blur while engaging in epistemic games (Shaffer 2008) that simulate professional jobs such as journalists, engineers, and architects, among others. This avenue of research leads to technology enhanced dramas or plays, which fosters early interest and early life commitment to some future career. Both clusters will impact schools profoundly.

The advent of the digital classroom wave has heralded a new era of formal education since the industrial revolution. Actually, long before we had computers, Sidney Pressey (1926), most probably the first dream-based researcher in this field, had proclaimed that the teaching machine he invented in 1920's would lead 
to great change in education. To some degree he was right, although change will come not through his machine but through e-books; not 80 years ago but in 20 years from now (a century after his proclamation). It is true that so far digital technology has not changed our education system in any fundamental way. Perhaps we have not yet approached the moment before dawn. Perhaps in 20 years there will still be no great changes in classrooms. But we as researchers must establish a growing number of compelling and sustainable digital classrooms, showing fundamental changes and paving the road for the arrival of great changes. With our endeavor, many fundamental problems at the heart of education we will reveal; many fundamental changes we will witness. But some fundamentals will not change-learning is joyful and teaching is caring.

\section{Acknowledgements}

The author would like to dedicate this paper to two retired English researchers, John Self and Robert Lewis. Both of them have helped Taiwanese researchers in different ways: one on establishing the ICCE conference series and the other on assisting publications in this journal. In addition, the author would like to thank for the reviews: Tom Anderson, Sherry Chen, Chih-Wei Hue, Kinshuk, Hwa-Wei Ko, Yu-Min Ku, Robin Lin, Chee-Kit Looi, Lim Cher Ping, Jeremy Roschelle, David Williamson Shaffer, and Mike Sharples. As a provocative paper, the author does not expect that they agree on this paper in any extent, but does appreciate their reviews to help shape this paper so that it can be more useful to the reader. Finally, the author is especially grateful for the help and patience as well as the invitation to write this paper by the editor-in-chief of this journal, Charles Crook. This research was supported by the National Science Council of the Republic of China, Taiwan (NSC-98-2631-S-008-001).

\section{References}

Biber D., Johansson S., Leech G., Conrad S. \& Finegan E. (1999) Longman Grammar of Spoken and Written English, pp. 65, British National Corpus, Pearson Longman.

Bloom B.S. (1980) All Our Children Learning, New York: McGraw-Hill.

Bloom B.S. (1984) The 2 sigma problem: the search for methods of group instruction as effective as one-on-one tutoring, Educational Researcher, 13, $4-16$. 
Borgman C.L., Abelson H., Dirks L., Johnson R, Koedinger K.R., Linn M.C., Clifford A. Lynch C.A., Oblinger D.G., Pea R.D., Salen K., Smith M.S., \& Szalay A. (2008) Fostering learning in the networked world: The cyberlearning opportunity and challenge. pp. 12, A 21st Century Agenda for the National Science Foundation, Report of the NSF Task Force on Cyberlearning.

Chan T.W. (1991) Integration-kid: A learning companion system. In Mylopolous J. \& Reiter R. (Eds.), In Proceedings of the 12th International Conference on Artificial Intelligence (Vol. 2, pp. 1094-1099). Australia, Morgan: Kaufmann Publishers, Inc.

Chan T.W. (1996) Learning companion systems, social learning systems, and intelligent virtual classroom, Journal of Artificial Intelligence in Education, 7 (2), 125-159.

Chan T.W. \& Baskin A.B. (1988) Studying with the prince: the computer as a learning companion, In Proceedings of ITS'88, Montreal, Canada, 194-200.

Chan T.W. \& Baskin A.B. (1990) Learning companion systems. In C. Frasson \& G. Gauthier (Eds.), Intelligent Tutoring Systems: At the Crossroads of Artificial Intelligence and Education, pp. 6-33, New Jersey: Ablex Publishing Corporation.

Chan T.W., Hue C.W., Chou C.Y. \& Tzeng O.J.L. (2001) Four spaces of network learning models, Computers and Education, 37, 141-161.

Chan T.W. \& Chou C.Y. (1997) Exploring the design of computer supports for reciprocal tutoring, International Journal of Artificial Intelligence in Education, 8, 1-29.

Chan T.W., Chung Y.L., Ho R.G., Hou W.J. \& Lin G.L. (1992) Distributed learning companion systems-West revisited, In Proceedings of ITS'92, C. Frasson, G. Gauthier, and G. McCalla, (eds.), Lecture Notes in Computer Science, Springer-Verlag, 608, 643-650. 
Chan T.W., Chou C.Y., Lee M.F. \& Chang M.H. (1995) Reciprocal-tutoring-kids: tutor-tutee role playing systems, In Proceedings of AIED'95, Washington, DC, USA, 226-233.

Chan T.W., Hue C.W., Chou C.Y. \& Tzeng O.J.L. (2001) Four Spaces of Network Learning Models, Computers \& Education, 37, 141-161.

Chan T.W., Roschelle J., Hsi S., Kinshuk, Sharples M., Brown T., Patton C., Cherniavsky J., Pea R., Norris C., Soloway E., Balacheff N., Scardamalia M., Dillenbourg P., Looi C. K., Milrad M., \& Hoppe U. (2006) One-to-one technology-enhanced learning: An opportunity for global research collaboration, Research and Practice in Technology Enhanced Learning, 1(1), 3-29.

Chang C.Y., Sheu J.P. \& Chan T.W. (2003a) Concept and design of ad hoc and mobile classrooms, Journal of Computer Assisted Learning, 19 (3), 336-346.

Chang S.B., Lin C.J., Ching E., Cheng H.N.H., Chang B., Chen F.C., Wu D. \& Chan T.W. (2009) EduBingo: developing a content sample for the one-to-one classroom by the content-first design approach, Educational Technology \& Society, 12 (3), 343-353.

Chang L.J., Yang J.C., Yu F.Y. \& Chan T.W. (2003b) Development and evaluation of multiple competitive activities in a synchronous quiz game system. Innovations in Education and Training International, 40 (1), 16-26.

Chang L.J., Chou C.Y., Chen C.H., and Chan T.W. (2004) An approach to assisting teachers in building physical and network hybrid community-based learning environment: The Taiwanese experience. International Journal of Educational Development, 24 (4), 383-396.

Chang B., Cheng N.H., Deng Y.C. \& Chan T.W. (2007) Environmental design for a structured network learning society, Computers and Education, 48 (2), 234-249.

Chen Y.S., Kao T.C., \& Sheu J.P. (2003) A mobile learning system for scaffolding bird watching learning, Journal of Computer Assisted Learning, 19 (3), 347-359. 